\title{
Relacionamentos Interpessoais Formal e Informal: Interação das Redes no Ambiente Acadêmico
}

\author{
Formal and Informal Interpersonal Relationships: Interaction of Networks in the \\ Academic Environment
}

\author{
Sandra Bergamini Leonardo ${ }^{1}$ \\ (D) https://orcid.org/0000-0003-2815-387X \\ Milton Carlos Farina ${ }^{1}$ \\ (D) https://orcid.org/0000-0003-0551-8282 \\ Taís Pasquotto Andreoli ${ }^{1}$ \\ (iD) https://orcid.org/0000-0002-9173-9294 \\ Ana Paula Morais Boteon de Lima ${ }^{1}$ \\ (D) https://orcid.org/0000-0003-1440-8843
}

Universidade Municipal de Sao Caetano do Sul, Programa de Pós-graduação em Administração, São Caetano do Sul, SP, Brasil ${ }^{1}$

Artigo recebido em 20.02.2018. Última versão recebida em 14.12.2018. Aprovado em 07.02.2019. 


\title{
Resumo
}

A literatura acadêmica apresenta conceitos que são explorados pelo seu aspecto formal e informal. Também enfatiza que os relacionamentos interpessoais informais complementam e contribuem de forma sinérgica com os relacionamentos formais que ocorrem nas diversas atividades humanas. Alguns autores estudaram a similaridade entre as partes formal e informal, outros indicaram que se poderia estudar os efeitos conjuntos da interação ou o delineamento dos limites da parte informal pela parte formal ou se ambas apresentariam influências recíprocas. Neste trabalho são comparadas as redes sociais formais e informais de duas turmas distintas de alunos universitários e em momentos diferentes para verificar a existência da interação entre os elementos formais e informais dessas redes. Foi realizado um estudo de campo de caráter exploratório com auxílio da análise de redes sociais por meio do software Ucinet 6.0 e Netdraw. Foram coletadas várias medidas com base na percepção dos alunos e a análise dos dados indicou resultados não condizentes com a literatura, indicando a não ocorrência de relação entre os aspectos formal e informal. Dada a importância dessa interação, cabe aos professores e à instituição de ensino prover meios para que isso ocorra. Os resultados indicam a necessidade de mais estudos científicos a respeito do tema.

Palavras-chave: análise de redes sociais; redes formais; redes informais; estudante universitário.

\begin{abstract}
The academic literature presents concepts that are explored by their formal and informal aspects. In addition, it is emphasized that informal interpersonal relationships complement and contribute synergistically with the formal relationships that occur in the various human activities. Some authors have studied the similarity between the formal and informal parts, others have indicated that one could study the joint effects of interaction or the delineation of the boundaries of the informal part by the formal part or if both would have reciprocal influences. In this work we compare the formal and informal social networks of two distinct groups of university students and at different moments to verify the existence of the interaction between the formal and informal elements of these networks. An exploratory field study was carried out with the help of social networks analysis through the software Ucinet 6.0 and Netdraw. Several measures were collected based on the students' perception and the analysis of the data indicated results that were not consistent with the literature, indicating the non-occurrence of a relationship between the formal and informal aspects. Given the importance of this interaction, it is up to the teachers and the educational institution to provide the means for this to occur. The results indicate the need for more scientific studies on the subject.
\end{abstract}

Keywords: social network analysis; formal networks; informal networks; university student.

JEL Code: L14, L84, O17. 


\section{Introdução}

A análise das redes engloba o estudo tanto da sua estrutura geral quanto dos padrões de relacionamento existentes entre seus atores, o que permite uma compreensão ampla acerca da dinâmica das relações sociais nelas presentes. Por esse motivo, o estudo da análise das redes sociais vem adquirindo crescente importância e sendo gradativamente disseminado.

Por rede social entende-se, de maneira sucinta, um conjunto de nós e elos interligados que representam os atores e as relações que compartilham, podendo ser visualmente explicativos (Brandes, Kenis, \& Raab, 2005). Nesse contexto, um conceito inerente à análise das redes sociais se refere à formalidade ou informalidade, ou seja, o quanto a rede social corresponde ao que foi previamente prescrito e estruturado na forma de obrigações e tarefas a serem desenvolvidas pelos atores envolvidos (formal) e, por outro lado, o quanto a rede social diz respeito ao que surge de maneira espontânea entre eles. Krackhardt e Hanson (1993) enfatizam que por meio da estrutura informal se realiza grande parte do trabalho que ocorre em uma organização.

Os autores Conde e Farias (2016) fizeram um levantamento bibliográfico que indicou poucos estudos a respeito dessa temática no âmbito da análise de redes sociais, além do que as relações informais contribuem para difundir conhecimento na empresa superando barreiras da estrutura formal e que a informalidade é outro modo de se estudar uma organização. Dessa forma há a necessidade de uma compreensão mais holística no sentido de comparar e avaliar as similaridades e diferenças entre as redes formal e informal (McEvily, Soda, Tortoriello, 2014; Soda \& Zaheer, 2012). Essa lacuna de pesquisa se torna ainda mais evidente ao se tratar de ambientes de ensino, visto que eles demandam interação e troca de informação, ideias e conhecimentos, gerando maior sinergia entre os alunos, tendo em vista melhores desempenhos e resultados (M. R. F. Teixeira, 2011), que deve ocorrer no período de tempo em que realizam o curso juntos.

O ambiente de uma instituição de ensino está inserido em um ambiente mais amplo no qual alunos, professores e gestores se relacionam com a sociedade e com os negócios, formando cidadãos e trabalhadores que atuarão no mercado de trabalho além do que as empresas têm o seu aprendizado por meio das pessoas que aprendem, uma vez que o aprendizado da organização não ocorre sem o aprendizado das pessoas (Schneider, 2002).

As regras, direitos e deveres dos alunos quando estão frequentando um curso em uma instituição de ensino, representam a estrutura formal que os impele na realização de tarefas individuais e em grupo, com o objetivo de obter conhecimento e de prepará-los para atuar como profissional. As relações de amizades e de outras atividades que ocorrem entre os alunos representam a parte informal que é uma característica também presente em outras instituições e organizações.

À luz do exposto apresenta-se a questão/problema de pesquisa: Quais são e como ocorrem os padrões de interação entre a rede formal na qual os alunos de uma turma tratam de assuntos profissionais, trabalhos e estudo em conjunto e a rede informal relativa a assuntos de ordem pessoal que ocorrem nas salas de aula?

O trabalho tem como objetivo comparar as estruturas das redes sociais informais e formais de duas turmas distintas de alunos universitários, com base nas suas percepções e avaliações próprias, em diferentes períodos de relacionamento.

A verificação dos padrões de interação entre as redes com base nas medidas fornecidas pela análise de redes sociais aplicadas nas duas turmas de alunos pode oferecer indícios a respeito da existência ou não da interação entre as redes formais e informais e se houver, como ocorre essa interação baseada nos relacionamentos presentes em uma turma, dentro e fora da sala de aula.

McEvily, Soda e Tortoriello (2014) baseados na literatura, argumentam que as redes formal e informal foram pesquisadas de forma separada e que a análise conjunta fornece uma melhor 
compreensão da organização e inclusive explicam parte da performance de seus colaboradores. Segundo os autores, os estudos nos anos de 1960 e 1970 estavam mais centrados nos arranjos formais da organização enquanto que nos anos 1990 e início de 2000, centravam mais nos elementos informais do funcionamento da organização, indicando a desconexão e a independência dos temas e a falta de uma compreensão do funcionamento de uma organização baseada em uma teoria que integrasse as duas estruturas formal e informal. Pode-se ainda perguntar se existe influência de uma rede sobre a outra e em quais condições e de que forma a mesma ocorre.

No caso das salas de aula, pode-se analisar a influência que os laços informais (amizade, confiança etc.) têm sobre os laços formais que significam a realização de tarefas individuais ou em grupos, impostas pelos professores nas disciplinas e nas regras da instituição de ensino, em diferentes períodos de relacionamento, enquanto realizam o curso.

O papel da análise de redes sociais neste trabalho é o de apresentar medidas das redes formal e informal com o objetivo de compará-las e as medidas da centralidade dos atores nesse caso, os alunos das turmas de uma universidade. Para esse assunto, a literatura apresenta também, pesquisas a respeito das diferenças entre os gêneros que neste trabalho serão analisados. Os resultados oferecem caminhos que podem ser trilhados no mesmo tipo de análise em outros tipos de organizações como públicas ou privadas, por se tratar dos relacionamentos entre os colaboradores que vivenciam tanto a estrutura formal como a informal nos seus ambientes de trabalho.

O foco está restrito aos padrões de relacionamento entre atores comuns que devem se relacionar na realização de diversas tarefas impostas pela estrutura formal, representadas pela instituição de ensino e pelos professores das disciplinas. Trabalhos futuros devem levar em conta outros atores como professores, diretores e outros que também fazem parte das organizações. A análise de redes sociais pode oferecer medidas que, com base nos resultados, poderão ser utilizadas nesses estudos futuros.

\section{Referencial Teórico}

O referencial teórico foi dividido em três partes, primeiramente discorrendo sobre a análise das redes sociais, definições e medidas, em seguida apresentando o tema das redes formais e informais em organizações e, finalmente, abordando redes formais e informais.

\section{Análise de redes sociais}

A palavra rede provém do latim retis e significa entrelaçado ou entrelaçamento de fios. Essa definição remete à ideia de formação de laços e ligações, assim como da existência de nós entre eles. Também dela se pode observar a característica básica de uma rede que, aplicada ao âmbito social, diz respeito aos múltiplos relacionamentos existentes entre os diversos atores que a compõem, que se utilizam dessas relações para realizarem trocas, ora como receptores, ora como ofertantes (Meirelles, Sacomano, Telles, \& Siqueira, 2014a). Também nesse sentido, Bastos e Santos (2007) conceituam rede como interações entre os atores que, por meio do compartilhamento de interesses e de situações vividas em comum, relacionam-se para se comunicar, trocar conhecimentos e se ajudar mutuamente.

Ainda que as redes de conexões existam desde os primórdios da humanidade, apenas nas últimas décadas os estudos começaram a direcionar esforços em investigá-las e compreendê-las (Marteleto, 2001). Segundo a autora, as redes poderiam ser geridas como ferramentas organizacionais no sentido de entender a experiência pessoal de cada ator a fim de se conduzir uma perspectiva global. Com isso, terse-ia a análise "global organizada", com foco tanto na independência individual de cada ator como na interdependência coletiva da rede (Lipnack \& Stamps, 1992, p. 19),

A análise das redes sociais possibilita uma maior compreensão acerca da estrutura geral das redes e das relações existentes entre seus atores (Conde \& Farias, 2016; Giglio \& Ryngelblum, 2009; 
Meirelles, Sacomano, Telles, \& Siqueira, 2014b). Nesse sentido, diversos elementos podem ser investigados, como nós, posições, ligações e fluxos, assim como variados fatores podem ser explorados, como a localização e a relevância de cada ator, os diferentes graus de densidade e as centralidades das conexões. Como consequência, multiplicam-se as possibilidades de mensuração, de acordo com as medidas a serem adotadas.

De acordo com Macambira e Bastos (2009) e Silva, Costa, Zamberlan e Costa (2011), a análise de rede social deste estudo possui foco estrutural, no sentido de compreender tanto sua perspectiva macro quanto micro. Foram utilizadas as medidas de centralidade: grau (degree: indegree e outdegree), intermediação (betweenness) e proximidade (closeness), assim como de densidade (density), reciprocidade (reciprocity) e centro-periferia (core-periphery).

Primeiramente, em relação à centralidade, o grau (degree) mede a quantidade de laços existentes entre os atores da rede, indicando quantos laços cada ator possui com os demais integrantes da rede (Marteleto, 2001; Wasserman \& Faust, 1994). A partir do grau, é possível compreender o funcionamento geral da rede, especificamente em relação à atuação de cada ator, por meio da análise de suas relações com os demais atores. Dessa forma, quanto maior o número de vínculos (laços) de um ator, maior seu grau, o que indica uma posição mais favorecida, que troca mais informações e, assim, com maior capacidade de influência na rede. O grau (degree) se divide em indegree e outdegree que se diferenciam pelo sentido da ligação, sendo a primeira referente à recepção (o ator $\mathrm{A}$ é procurado pelo ator $\mathrm{B}$ para $\mathrm{a}$ troca de informação, por exemplo) e a segunda à emissão do laço (A procura B para trocar informação).

Em segundo lugar, tem-se a intermediação (betweenness) definida como uma interação dependente entre atores, ou seja, o quanto um ator concentra o controle da comunicação, situando-se como intermediário entre seus pares (M. R. F. Teixeira, 2011). Pode-se inferir que, quanto maior a intermediação de um ator, maior sua capacidade de influência, já que as demais relações acabam dependendo dos laços entre os atores intermediários. Uma possibilidade de análise decorrente da medida de intermediação é o levantamento de caminhos geodésicos alternativos, caracterizados como os possíveis caminhos mais curtos que podem ser seguidos para um ator se relacionar com os outros integrantes da rede.

Com base na análise dos caminhos geodésicos, a medida proximidade (closeness) indica a distância existente entre os diversos atores da rede. Dessa forma, quanto maior os valores de proximidade, menores as distâncias entre os atores da rede, que tendem a aumentar também suas influências. Essa medida se divide em incloseness e outcloseness, que se diferenciam pelo sentido da ligação, sendo a primeira referente à recepção e a segunda à emissão.

Por sua vez, a densidade mostra o número de ligações existentes entre todos os atores de uma rede, indicando o seu nível geral de conectividade e compartilhamento (M. R. F. Teixeira, 2011). Quanto maior o número de ligações relatadas em uma determinada rede, maior sua densidade, ou seja, maior relacionamento entre seus atores.

Já, a reciprocidade se refere ao grau em que as relações existentes na rede são bidirecionais, fluindo em ambos os sentidos (Azevedo \& Rodriguez, 2010; Petterson \& Castro, 2016; Wasserman \& Faust, 1994). A reciprocidade se preocupa não apenas em detectar a interligação dos atores, mas também em identificar a mútua troca entre os pares. Quanto maior o nível de reciprocidade de uma rede, melhores são as relações existentes.

Por fim, a medida centro-periferia permite a identificação dos centros e das periferias das redes, o que contribui para compreender a coesão dos grupos e a força de seus laços (Fittipaldi, Donaire, Farina, \& Araújo, 2014). Os centros se configuram como um espaço de concentração de muitos laços, nos quais os atores se encontram mais fortemente ligados entre si e, por isso, representam, geralmente, um subgrupo mais coeso. As periferias, por outro lado, caracterizam-se por espaços com poucos laços, nos quais os atores se ligam de maneira mais fraca e, assim, tendem a formar subgrupos menos coesos. A comparação dessas medidas das redes formal e informal serve como indicador para avaliar as duas redes em termos dos padrões de relacionamento, enfatizados pela literatura. 
Para que as redes formal e informal sejam consideradas com padrões similares de interação, as medidas da estrutura da rede (densidade, reciprocidade e centro-periferia) devem ter valores próximos entre si, e o mesmo raciocínio vale para as medidas de centralidade dos atores. Para se constatar que o relacionamento aumenta e se fortalece com o tempo, as medidas das redes com tempo maior de relacionamento devem ser superiores à com tempo menor de relacionamento. Esse tipo de raciocínio está baseado no trabalho de Meirelles, Sacomano, Telles e Siqueira (2014b).

\section{Redes sociais em ambientes organizacionais}

Burkhardt (1994) realizou um estudo longitudinal sobre a influência social e o papel das relações interpessoais na disseminação de crenças, atitudes e comportamentos em uma organização após uma mudança tecnológica. A maioria dos achados mostrou que, embora os indivíduos com quem uma pessoa interage influenciem diretamente as crenças sobre sua habilidade pessoal, as atitudes e os comportamentos são mais afetados por colegas de trabalho com o mesmo grau hierárquico, como é o caso de estudantes em uma sala de aula e que podem ser avaliados pelas medidas de centralidade.

Waldstrom (2001) comparou gerentes homens e mulheres e constatou que as mulheres tendem a participar de dois tipos de redes na organização. Uma das redes é formada com outras mulheres com objetivo de amizade e a outra é uma rede com homens visando a carreira profissional. Ainda nessa questão, outro fato interessante de análise e comparação das redes formal e informal, segundo Mohammadi, Hosseinzadeh e Kazemi (2012), é que a mulher tende a utilizar mais a rede informal dentro da organização, quando comparada ao homem, quando se trata de obter melhores cargos e de ascendência na carreira. $\mathrm{O}$ mesmo pode ocorrer nos relacionamentos entre alunas quando comparadas com os alunos.

O trabalho de Zanini, Migueles, Comerauer e Mansur (2013) identificou a confiança no colega de profissão como fator relevante para a coordenação informal. Esses autores realizaram seus estudos em uma unidade de operações especiais da polícia e observaram que, embora a liderança seja igualmente relevante para estabelecer a confiança entre os membros das equipes, os maiores níveis de confiança ocorreram na relação com um colega imediato. Esse conceito pode explicar diversos tipos de relacionamentos tanto na rede formal quanto informal por ser um elemento comum às duas redes e é característico quando os alunos trabalham em grupo na realização de tarefas determinadas pelos professores.

Observa-se que, nos trabalhos citados, a proximidade com os colegas foi fator decisivo para delinear comportamentos que podem ser representados e analisados na análise de redes sociais (medidas de centralidade, reciprocidade entre outras). Todavia isso não ocorreu no trabalho de Miranda, Liboreiro e Borges (2017) quando estudaram como as redes sociais intraorganizacionais podem influenciar a adequação do indivíduo à organização. Dentre os achados desses autores, chama a atenção o fato de as relações de proximidade e intermediação dos relacionamentos não terem sido confirmadas como fatores que influenciam a adequação do trabalho com a organização. Embora os autores tenham enfatizado que o fato de o estudo ter sido desenvolvido em micro e pequenas empresas do setor de serviços possa ter influenciado os resultados, estes são importantes ao revelarem o possível descasamento entre relacionamentos informais e formais em um ambiente organizacional.

Vieira e Neiva (2009) realizaram um mapeamento das redes de amizade e comunicação de uma empresa durante a implementação de mudanças organizacionais e onze meses após essa implementação, os resultados encontrados revelaram impactos mais significativos na rede de amizade, pois, mesmo ocorrendo redução do tamanho, a rede se tornou mais densa. Interessante notar que as redes se reorganizaram para se adaptar à nova realidade organizacional. Alguns atores perderam poder enquanto outros adquiriram status (centralidade de grau). A rede de amizade apresentou perda de laços por conta da saída e/ou troca de departamento pelos empregados, porém, novos laços foram estabelecidos e se apresentaram como mais fortes, com aumento da densidade e com a diminuição da distância geodésica e do diâmetro da rede (centro-periferia). 
O trabalho de Vieira e Neiva (2009) evidencia que, além das mudanças organizacionais implementadas, o tempo foi fator relevante para que ocorressem alterações na rede estudada. Pode-se então, considerar que mudanças não só de origem organizacional, mas também temporal, que ocorrem em um ambiente organizacional qualquer ou universitário, podem afetar as redes de relacionamento. No caso específico do ambiente universitário, as mudanças podem estar relacionadas à entrada de novos alunos e/ou saída de alunos veteranos, alterações nos cursos, formação de novos grupos para trabalhos acadêmicos, nova visão e/ou objetivos por parte dos discentes, motivos estes que não diferem, substancialmente, daqueles que afetam as redes de relacionamento das organizações, como: demissões e contratações, alterações no plano estratégico das instituições, remanejamento de colaboradores, entre outros.

Outra questão a ser considerada quando da análise de redes sociais em ambiente organizacional, universitário ou esportivo está relacionada com a influência que alguns atores de determinada rede exercem sobre os demais. Pesquisa realizada por Krackhardt e Hanson (1993) em um banco mostrou que $80 \%$ da rotatividade de funcionários estavam relacionados muito mais com o relacionamento destes com atores chave em suas redes de confiança do que com a organização formal. De fato, quando estes atores chave deixavam a instituição bancária, outros os seguiam, o que confirma a influência exercida por alguns atores em detrimento daquela exercida pela própria instituição.

Outro aspecto que chama a atenção é a centralidade dos atores (grau, intermediação e proximidade) em uma rede de confiança. Genoíno e Siqueira (2017) estudaram a relação da centralidade em equipes esportivas com o comprometimento organizacional, com a qualidade técnica e com o tempo na equipe e os resultados da pesquisa mostraram que os atletas que tiveram posições mais centrais (maiores medidas de centralidade) dentro da rede foram aqueles com maiores pontuações nessas três variáveis. Os autores concluíram que profissionais mais comprometidos e qualificados e com mais tempo dentro de uma organização podem gozar de maior confiança no ambiente no qual estão inseridos, o que contribui para fortalecer a questão da influência de figuras centrais em redes informais. Em ambientes organizacionais e universitários também é de se esperar que existam atores que exerçam influência sobre os demais, inclusive na tomada de decisão que pode envolver até a mudança de comportamento e/ou escolhas profissionais.

A análise de redes sociais no ambiente acadêmico ganha evidência neste trabalho devido à própria concepção de universidade, considerada um espaço propício para o compartilhamento dos mais diversos conhecimentos e experiências. Sendo assim, a compreensão acerca das redes sociais existentes nesse contexto, como elas estão estruturadas e como funcionam, torna-se fundamental para a estimação do real valor desses ambientes, como é o caso das instituições de nível superior (M. R. F. Teixeira, 2011).

A questão da interação em sala de aula e sua necessidade enquanto fator de aprendizado compõe o discurso de muitos profissionais de ensino, que defendem a promoção e aprimoramento da construção de conhecimentos pelos próprios alunos e suas interações, estratégia denominada como integraçãosocial (Davis, Silva., \& Esposito, 1989). Outro ponto é que as exigências das universidades geralmente demandam que os estudantes permaneçam muitas horas em sala de aula, ou mesmo acumulem atividades em grupo extraclasse, de forma que a universidade e as relações que nela são desenvolvidas se tornam imperativas da vida dos estudantes (M. T. Teixeira \& Reis, 2012), o mesmo ocorrendo entre colaboradores nas organizações. Dessa forma, a comparação das medidas da análise de redes sociais relativas aos relacionamentos formais e informais contribui para a explicação do fenômeno estudado.

Como Kolaczyk e Csárdi (2014) apontam, as redes se tornam, cada vez mais, os meios pelos quais as informações podem ser difundidas e disseminadas, possibilitando a criação de conhecimentos. Segundo os autores, a análise das redes contribui para se mapear como essa troca de informações ocorre, mostrando também como os diversos atores colaboram para a criação de novos conhecimentos. Compreender a dinâmica das salas de aula, sua estrutura geral e dinâmica de relacionamentos, configurase, assim, como imprescindível contribuição ao estudo de redes sociais.

Essa necessidade de compreensão é ainda maior quando se pensa em uma perspectiva temporal, isto é, como as mais diferentes turmas em salas de aula se modificam e se adaptam com o passar do 
tempo, progredindo ou retrocedendo. Nesse sentido, espera-se que a dinâmica das relações existentes em uma turma de sala de aula de universitários calouros, recém-integrantes, seja diferente de uma turma mais velha, já estruturada e solidificada, como do terceiro ano (Carlotto, Teixeira, \& Dias, 2015; M. A. P. Teixeira, Dias, Wottrich, \& Oliveira, 2008). Segundo os autores, os estudantes que se integram socialmente desde o início de seus cursos aumentam suas chances de crescer pessoal e profissionalmente.

\section{Redes formais e informais}

A literatura apresenta e diferentes autores exploram os aspectos formal e informal relacionados a conceitos tais como a comunicação formal e informal (Basov \& Wuehr, 2012; Diniz, Santana, \& Rodriguez, 2012; Enyia \& Eze, 2016).

Autores realizaram estudos a respeito da educação formal e informal (Carlotto et al., 2015; M. A. P. Teixeira et al., 2008; M. R. F. Teixeira, 2011; M. T. Teixeira \& Reis, 2012; Marques \& Freitas, 2017).

Também foram realizadas pesquisas a respeito de rede formal e informal em escolas pública e privada (Nishi, 2014), em salas de aula sobre o comportamento dos alunos e em relação ao professor (McFarland, 2001) e redes sociais na escola pública (Nishi, Lobler, Costa, \& Lopes, 2014).

Do mesmo modo, a literatura apresenta estudos relacionados à organização e às estruturas formais e informais (Bastos \& Santos, 2007; Burkhardt, 1994; Genoíno \& Siqueira, 2017; Krackhardt \& Hanson, 1993; Maciel \& Camargo, 2015; McEvily et al., 2014; Meirelles et al., 2014a; Miranda, Liboreiro, \& Borges, 2017; Pascotto, Farina, Rodrigues, \& Dugo, 2013; Soda \& Zaheer, 2012; Vieira \& Neiva, 2009; Zanini, Migueles, Comerauer, \& Mansur, 2013).

As relações formais presentes nas organizações se configuraram como objeto de análise desde o início do estudo da administração, com o marco da Administração Científica, no início dos anos 1900. Porém, a possibilidade de informalidade nas relações dentro das organizações só começa a ser considerada com a segunda grande corrente de estudo da administração, a Escola de Relações Humanas, oriunda em meados de 1920. A partir dela, começa a ganhar importância o papel dos grupos sociais informais intraorganizacionais no sentido de se entender como eles se compõem e como isso influencia no desempenho do trabalho que, como consequência, impacta nos resultados organizacionais.

Nesse sentido, evidenciou-se que, basicamente, são dois os tipos de relações ou redes existentes nas organizações: a rede formal e a rede informal. $\mathrm{O}$ relacionamento formal é identificado pelo organograma da empresa e o relacionamento informal que gera sinergia e ainda não está bem explorado, principalmente na troca de informação e de conhecimento, segundo Ribeiro e Rodriguez (2016) que pesquisaram as relações de informação, conhecimento, amizade e confiança em um centro de pesquisas e desenvolvimento de projetos. Na sala de aula a rede formal é caracterizada pela instituição, pela diretoria e pelos professores que demandam obrigações e tarefas aos alunos. O relacionamento entre alunos caracteriza os colaboradores que atuam dentro da organização.

Uma metáfora que é utilizada de maneira recorrente pela literatura (McEvily et al., 2014; Meirelles et al., 2014b; Pascotto et al., 2013) para diferenciar esses dois constructos é a analogia proposta por Krackhardt e Hanson (1993). Os autores defendem que a organização formal diz respeito ao esqueleto da organização, à estrutura oficial que organiza e regulamenta o comportamento, e a organização informal se relaciona ao sistema nervoso central, ou seja, aos processos de pensamento, de ações e de reações da organização.

Para Bastos e Santos (2007) e Pascotto, Farina, Rodrigues e Dugo (2013), esses dois aspectos das organizações não só se complementam, mas, principalmente, influenciam-se. Nesse sentido, Pascotto et al. (2013) argumentam que a influência da rede social informal sobre a rede formal está na sua importância para o desenvolvimento e a formação de um ambiente propício para a troca de conhecimentos, experiências e informações. Em consonância, Bastos e Santos (2007) corroboram os 
autores supracitados ao defenderem que as relações informais possibilitam uma melhor circulação das informações intraorganizacionais, contribuindo para uma maior articulação de entendimentos acerca do comportamento organizacional. Outros autores também discorreram acerca disso, como Maciel e Camargo (2015), que defendem como vantagem a possibilidade de aumento do elo entre os integrantes de uma organização, bem como do senso de pertencimento e de identificação não só entre eles, mas com a organização como um todo.

Além disso, deve-se compreender a interação entre esses dois aspectos, tópico apontado como pouco explorado pela literatura (McEvily et al., 2014; Soda \& Zaheer, 2012). Nesse sentido, McEvily et al. (2014) argumentam que essa interação pode ocorrer de forma a criar uma sinergia dentro da organização e positivamente no desempenho individual de seus atores, decorrente, principalmente, da maior possibilidade de acesso às informações, ideias e conhecimentos, que se potencializa ao se considerar a reciprocidade das redes.

\section{Procedimento Metodológico}

Para atender ao objetivo proposto pelo trabalho, adotou-se como procedimento metodológico um estudo de campo de caráter exploratório, com o auxílio da análise de redes sociais por meio do software Ucinet 6.0 e Netdraw. A amostra foi de conveniência, selecionada entre as turmas do curso da Administração com a escolha de duas salas (turmas) e a coleta de dados se deu por meio da aplicação presencial de questionários junto a duas turmas distintas de estudantes universitários do curso de Administração de uma instituição municipal de ensino superior situada na região metropolitana da cidade de São Paulo. As turmas selecionadas foram do segundo e sexto semestres, denominadas de Turma 1, do ciclo básico, alunos com idade variando entre 17 e 28 anos, e Turma 2 do sexto semestre com idades variando entre 19 e 46 anos, nas quais se atingiu 93,3\% ( $n=42)$ e 90,2\% ( $n=55)$ dos alunos, respectivamente, segundo listas de chamada em vigor no momento da coleta de dados (agosto de 2016). Dessa forma, a amostra caracteriza-se como não probabilística, com objetivo de se avaliar e comparar a estrutura das redes, segundo os conceitos e medidas da análise de redes sociais, considerando também os dois tempos de vida acadêmica diferentes tanto das redes formais e quanto das informais. Os tempos de vida acadêmica são diferentes: uma turma do segundo semestre, que se pode considerar como iniciante, e uma turma do sexto semestre com um maior tempo de interação entre os alunos.

O instrumento de coleta de dados continha três blocos principais: o perfil dos respondentes (nome, idade e gênero), a identificação da existência de relacionamento pessoal (informal) e de relacionamento profissional (formal) com cada um dos colegas da turma (sim/não), e uma atribuição de nota a si mesmo, para avaliar seu próprio relacionamento informal e formal na sala de aula (escala de 0 a 10 , sendo zero nenhum relacionamento e 10, total relacionamento). A rede informal foi explicada aos alunos como a rede estabelecida entre eles para tratarem de assuntos pessoais, não relacionados às disciplinas e/ou ao curso, enquanto que a rede formal foi descrita como a rede estabelecida entre os alunos para tratarem exclusivamente de assuntos profissionais, diretamente relacionados às disciplinas e/ou ao curso.

As notas que os participantes atribuíram a si mesmos acerca do nível de relacionamento informal e formal foram tabuladas e ilustradas por figuras geométricas, de forma que o círculo representa a faixa que compreende as notas de zero a quatro (nível inexistente ou baixo de relacionamento com os demais colegas), o quadrado ilustra a faixa que compreende as notas de cinco a sete e o triângulo denota as notas de oito a dez (alto nível de relacionamento). Além disso, o gênero dos participantes também foi ilustrado por cores diferentes, sendo os atores masculinos representados na cor azul e os femininos na cor vermelha.

Foram utilizadas medidas de centralidade dos atores, destrinchadas em grau, intermediação e proximidade, e medidas estruturais das redes, tais como densidade, reciprocidade e centro-periferia. Foram escolhidos, como material de apoio, os programas NETDRAW para o mapeamento das redes sociais e o UCINET para a análise de suas medidas. Isso possibilitou a verificação tanto dos aspectos 
descritivos dos relacionamentos formal e informal, como a realização das análises estatísticas relacionadas a eles (Hanneman \& Riddle, 2005).

Três testes estatísticos não paramétricos foram utilizados: o teste de correlação de Spearman, a fim de verificar as correlações significativas entre as medidas adotadas, o teste de Wilcoxon, no intuito de comparar as medidas entre as redes formais e informais, e o teste de Mann-Whitney, para comparar as medidas das redes no decorrer do tempo. Optou-se pelos testes não paramétricos por serem mais adequados em situações de pesquisa que não exijam a normalidade dos dados. Também foi utilizado o teste $t$ de Student na comparação das notas médias que os alunos deram a si mesmos.

\section{Análise de Resultados e Discussão}

A seguir, são expostas as redes informais e formais da turma $1\left(2^{\circ}\right.$ semestre) e da turma $2\left(6^{\circ}\right.$ semestre). Nestas redes, estão inseridas as notas que cada aluno atribuiu a si considerando seu nível de relacionamento com os demais colegas (de 0-4 representadas por círculo, 5-7 por um quadrado e 8-10 por um triângulo). Também estão diferenciados os gêneros por cores, sendo azul para o masculino e vermelho para o feminino. Optou-se por inserir a legenda somente na Figura 1, já que foram mantidas as mesmas representações nas demais figuras.

As redes informal e formal formadas pelos alunos da turma 1 (Figuras 1 e 2) foram compostas por 42 atores (taxa de resposta de 93,3\%), sendo 24 do gênero masculino e 18 do gênero feminino, com idade média de 20 anos (mínima 17 e máxima 28).

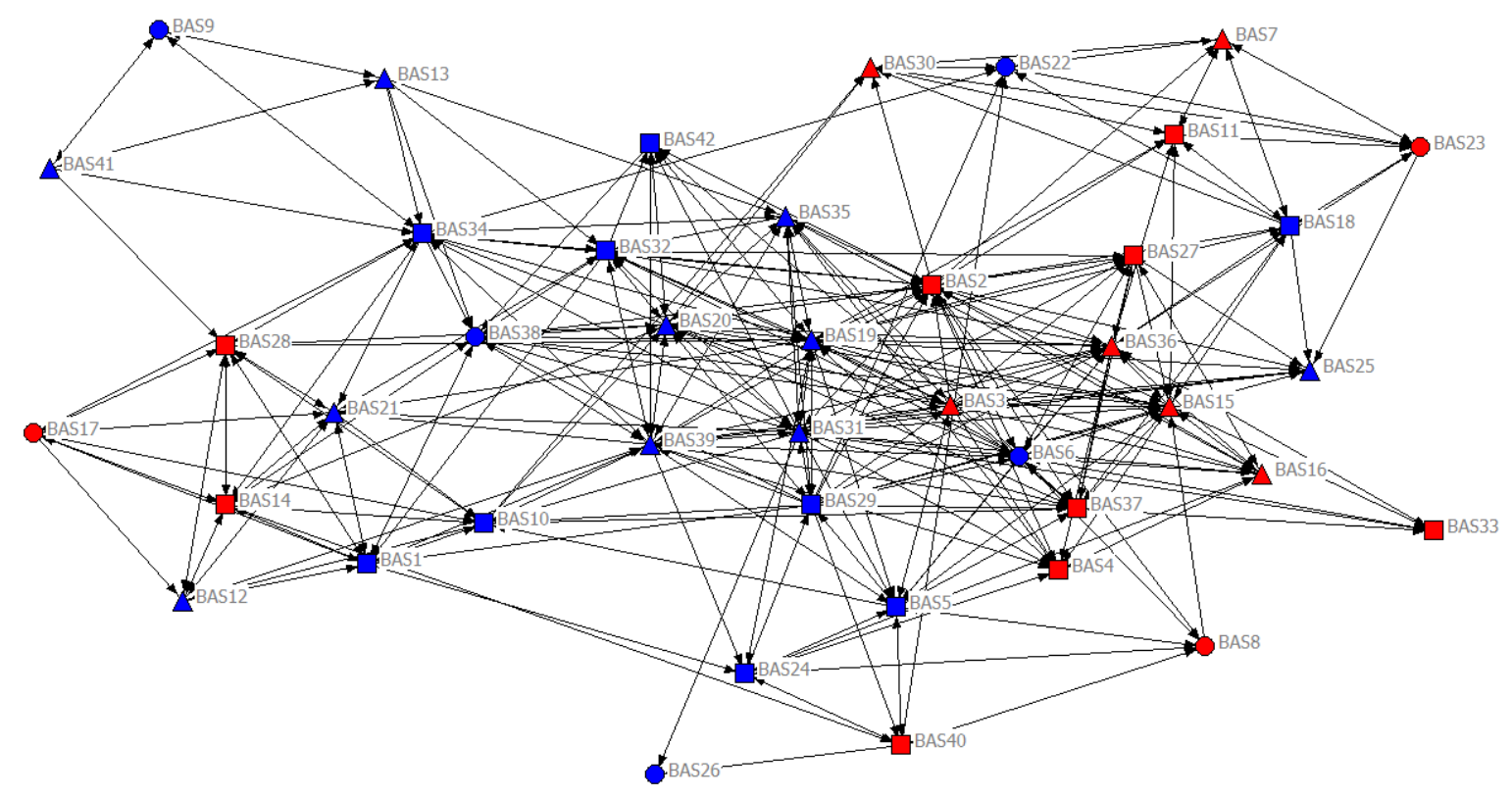

Figura 1. Rede Informal da Turma 1

Legenda: Gênero masculino (azul)/Gênero feminino (vermelho); Notas de 0-4 (círculo), 5-7 (quadrado) e 8-10 (triângulo). Fonte: Elaborada pelos autores. 


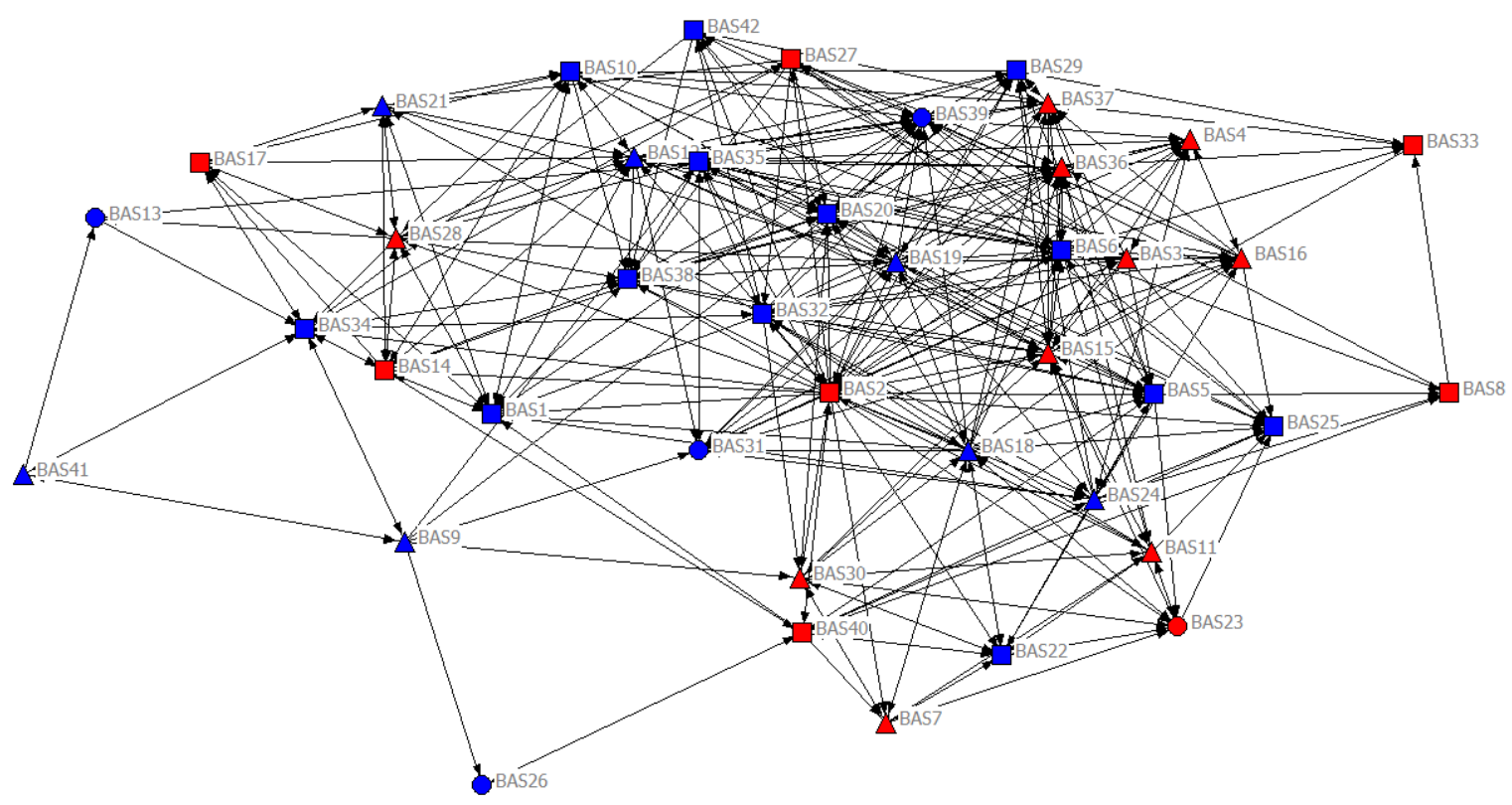

Figura 2. Rede Formal da Turma 1

Fonte: Elaborada pelos autores.

As densidades das duas redes são baixas: $22,5 \%$ para a rede informal e 21,9\% para a rede formal, isto é, de todos os relacionamentos possíveis entre os alunos, as redes são formadas com pouco mais de $20 \%$ das relações. Constata-se que deveria haver maior relacionamento entre os alunos, apesar de ser uma turma que ainda pouco se conhece. Pode-se dizer também, que as densidades apresentam valores próximos entre si.

As redes informal e formal formadas pelos alunos da turma 2 (Figuras 3 e 4 ) foram compostas por 55 atores (taxa de resposta de $90,2 \%$ ), sendo 20 do gênero masculino e 35 do gênero feminino, com idade média de 24 anos (mínima 19 e máxima 46).

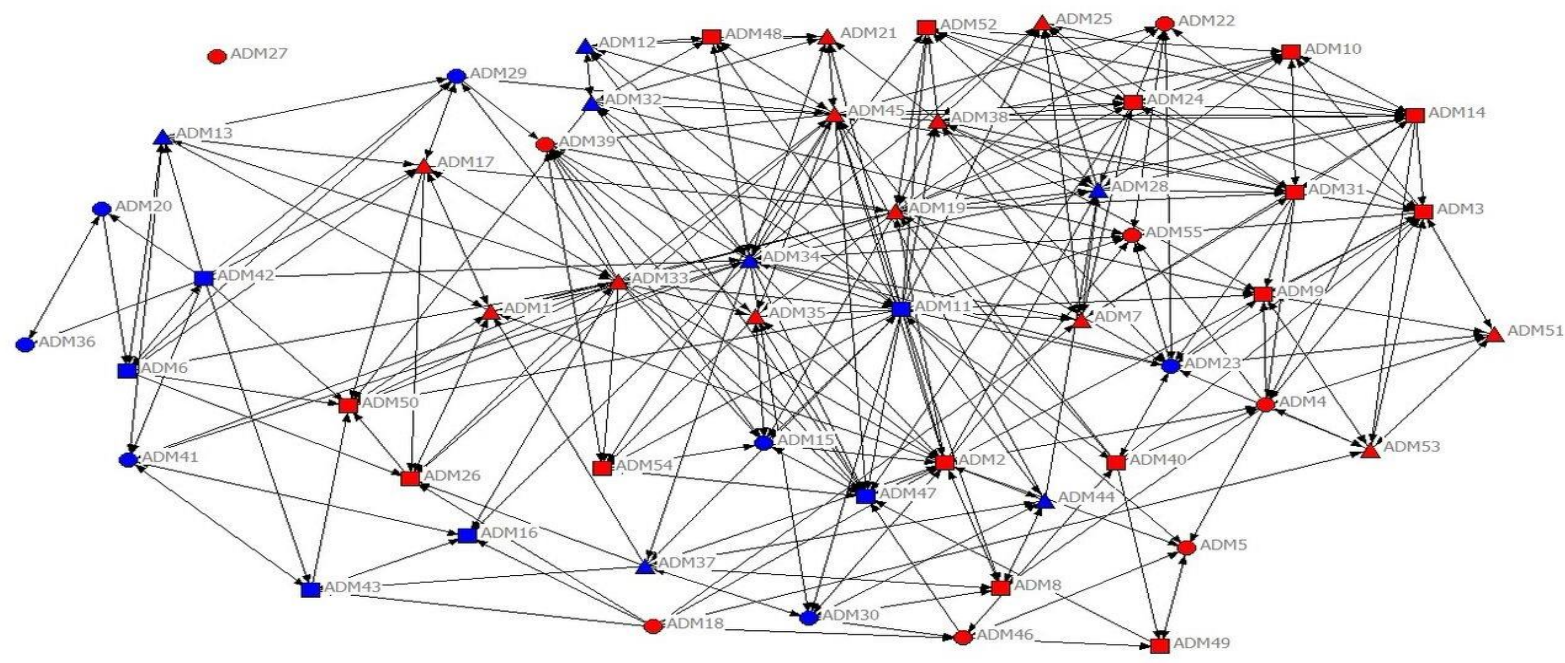

Figura 3. Rede Informal da Turma 2 Fonte: Elaborada pelos autores. 


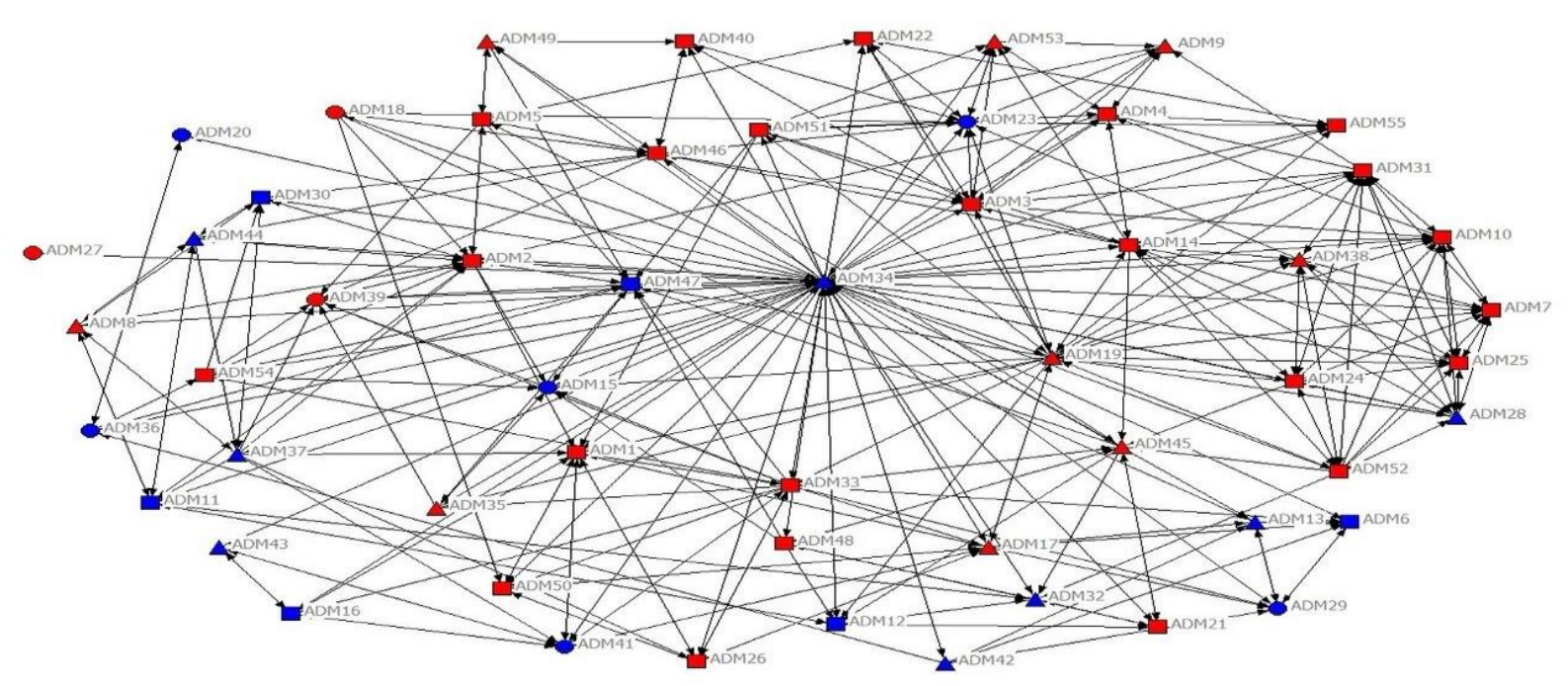

Figura 4. Rede Formal da Turma 2

Fonte: Elaborada pelos autores.

As densidades da turma 2, que tem mais tempo de relacionamento entre os alunos, também são baixas, porém de forma mais acentuada que a turma 1: densidade da rede informal com 11,6\% e formal com $11,9 \%$ de todos os relacionamentos que seriam possíveis. Esperar-se-ia, pelo menos, o oposto, isto é, valores maiores na turma (2) com mais tempo de relacionamento do que na turma (1) com menos tempo de relacionamento. Os resultados não corroboram os autores Bastos e Santos (2007) e Pascotto et al. (2013).

Os resultados buscaram verificar os relacionamentos existentes entre alunos que estão iniciando o curso, ou seja, no segundo semestre (Turma 1) e compará-los com os relacionamentos entre aqueles que já estão no sexto semestre (Turma 2) com maior tempo de convivência.

\section{Atribuição de nota}

Analisando as notas que os entrevistados se atribuíram, considerando seus níveis de relacionamento em sala, observou-se que houve uma maior concentração de alunos de ambas as turmas na faixa intermediária, que compreende as notas de 5 a 7 , seguida da faixa superior, que engloba as notas de 8 a 10 (Tabela 1$)$.

Observou-se também, variações entre as notas atribuídas pelos entrevistados, tanto na comparação entre as redes formal e informal de cada turma como na comparação entre as turmas.

Com relação ao relacionamento informal entre as turmas, um aspecto a se destacar foi o aumento da média das notas do gênero feminino, de 5,9 da turma 1 para 6,3 da turma 2, e uma queda da média das notas do gênero masculino, de 6,4 da turma 1 para 5,8 da turma 2. Com esse resultado, pode-se admitir que o gênero feminino, com o passar do tempo e com um maior período de convivência, tende a se atribuir notas mais altas na variável relacionamento, enquanto que o gênero masculino tende a se atribuir notas mais baixas. E essa constatação se evidencia quando comparamos o relacionamento formal entre as turmas. Embora a média das notas do gênero feminino tenha sofrido uma pequena variação para baixo, de 6,7 da turma 1 para 6,5 da turma 2, a média das notas do gênero masculino sofreu uma variação maior, de 6,5 da turma 1 para 5,6 da turma 2. Os resultados corroboram Waldstrom (2001) e Mohammadi et al. (2012). 
Tabela 1

Notas Atribuídas pelos Alunos

\begin{tabular}{|c|c|c|c|c|c|c|}
\hline \multirow[b]{3}{*}{ Nota } & \multicolumn{6}{|l|}{ Turma 1} \\
\hline & \multicolumn{3}{|l|}{ Informal } & \multicolumn{3}{|l|}{ Formal } \\
\hline & $\begin{array}{l}\text { Gênero } \\
\text { feminino }\end{array}$ & $\begin{array}{l}\text { Gênero } \\
\text { masculino }\end{array}$ & Geral & $\begin{array}{l}\text { Gênero } \\
\text { feminino }\end{array}$ & $\begin{array}{l}\text { Gênero } \\
\text { masculino }\end{array}$ & Geral \\
\hline Faixa de 0 a 4 & $4(22,2 \%)$ & $5(20,8 \%)$ & $9(21,4 \%)$ & $2(11,1 \%)$ & $4(16,7 \%)$ & $6(14,3 \%)$ \\
\hline Faixa de 5 a 7 & $8(44,5 \%)$ & $9(37,5 \%)$ & $17(40,5 \%)$ & $6(33,3 \%)$ & $13(54,1 \%)$ & $19(45,2 \%)$ \\
\hline Faixa de 8 a 10 & $6(33,3 \%)$ & $10(41,7 \%)$ & $16(38,1 \%)$ & $10(55,6 \%)$ & $7(29,2 \%)$ & $17(40,5 \%)$ \\
\hline \multirow[t]{3}{*}{ Média } & $\mathbf{5 , 9}$ & 6,4 & 6,2 & 6,7 & 6,5 & 6,6 \\
\hline & \multicolumn{6}{|l|}{ Turma 2} \\
\hline & \multicolumn{3}{|l|}{ Informal } & \multicolumn{3}{|l|}{ Formal } \\
\hline Nota & $\begin{array}{l}\text { Gênero } \\
\text { feminino }\end{array}$ & $\begin{array}{l}\text { Gênero } \\
\text { masculino }\end{array}$ & Geral & $\begin{array}{l}\text { Gênero } \\
\text { feminino }\end{array}$ & $\begin{array}{l}\text { Gênero } \\
\text { masculino }\end{array}$ & Geral \\
\hline Faixa de 0 a 4 & $8(22,9 \%)$ & $7(35,0 \%)$ & $15(27,3 \%)$ & $3(8,6 \%)$ & $6(30,0 \%)$ & $9(16,4 \%)$ \\
\hline Faixa de 5 a 7 & $15(42,9 \%)$ & $6(30,0 \%)$ & $21(38,2 \%)$ & $23(65,7 \%)$ & $6(30,0 \%)$ & $29(52,7 \%)$ \\
\hline Faixa de 8 a 10 & $12(34,3 \%)$ & $7(35,0 \%)$ & $19(34,5 \%)$ & $9(25,7 \%)$ & $8(40,0 \%)$ & $17(30,9 \%)$ \\
\hline Média & 6,3 & 5,8 & 6,0 & 6,5 & 5,6 & 6,1 \\
\hline
\end{tabular}

Nota. Fonte: Elaborada pelos autores.

Apesar das diferenças indicadas entre as notas médias, os testes t de Student aplicados indicaram que as diferenças entre as notas médias não são significativas ao nível de 5\% de confiança.

Foram testadas as notas médias das redes formal versus informal da turma 1 ( $p$-value $=0,35)$ e da turma 2 ( $\mathrm{p}$-value $=0,79$ ). A comparação das redes informais da turma 1 versus da turma 2 apresentou intervalo de $-1,57$ a 0,57 para a diferença entre as médias e, para a comparação das redes formais, apresentou intervalo de $-1,57$ a 0,17 , isto é, as diferenças de médias são consideradas com valor zero ao nível de $5 \%$ de confiança.

\section{Grau (Degree)}

A medida grau (degree), como já mencionado no referencial teórico, permite identificar a quantidade de contatos diretos que um ator possui dentro da rede, estando dividida em indegree e outdegree, sendo que a primeira representa os atores que são procurados para se relacionar por outros atores da rede e a segunda representa os atores que procuram relacionamento com outros componentes da rede.

Para a turma 1, em relação à rede informal, a medida indegree variou de 2 a 19 ligações, com maior concentração de alunos com valores 9 e 10, e a medida outdegree variou de 0 a 24, com maior concentração de alunos com valor 5. A variação das medidas em relação à rede formal foi semelhante, com a medida indegree variando entre 2 a 19 ligações, com maior concentração nos valores 8 e 9, e a medida outdegree variando entre 1 a 31 ligações, com maior concentração nos valores 7 e 8 .

Para a Turma 2, em relação à rede informal, pôde-se observar que a medida indegree variou de 0 a 13 ligações, com maior concentração nos valores 5, 6, 8 e 9, e a medida outdegree variou de 0 a 26 ligações, com maior concentração nos valores $2,3,4$ e 5 . A variação dessas medidas na rede formal foi mais expressiva, com a medida indegree variando de 1 a 13 ligações, com maior concentração nos 
valores 6 e 7, e a medida outdegree variou de 0 a 54 ligações, com maior concentração nos valores 3, 5 , 6 e 8.

As medidas de indegree e outdegree não apresentaram diferenças significativas entre as redes informal e formal para ambas as turmas (teste de Wilcoxon). Isto é, as médias das diferenças entre os números de ligações recebidas (outdegree) por aluno podem ser consideradas iguais entre as redes formais e informais em ambas as turmas, assim como para os números de ligações realizadas (indegree).

Entretanto, foram encontradas diferenças significativas entre as duas turmas para as quatro medidas analisadas, verificadas por meio do teste não paramétrico de Mann-Whitney. Primeiramente, foram observadas diferenças significativas entre os indegrees e outdegrees informais ( $U=719, p=0,001$ e $\mathrm{U}=787, \mathrm{p}=0,007$, respectivamente), sendo ambas as medidas maiores para a Turma 1 (Mean Rank=59,38 e 57,76, respectivamente) do que para a Turma 2 (Mean Rank=41,07 e 42,31, respectivamente).

Resultado semelhante ocorreu em relação à rede formal, com diferenças significativas observadas entre os indegrees e outdegrees formais ( $\mathrm{U}=778, \mathrm{p}=0,006$ e $\mathrm{U}=789, \mathrm{p}=0,007$, respectivamente), sendo novamente ambas as medidas maiores para a Turma 1 (Mean Rank=57,98 e 57,71, respectivamente) do que para a Turma 2 (Mean Rank=42,15 e 42,35, respectivamente). Ou seja, os resultados não confirmam a literatura pois, verificou-se que existem mais relacionamentos (ligações) entre os alunos iniciantes, do segundo semestre (Turma 1), do que entre os alunos veteranos, do sexto semestre (Turma 2). Esses resultados não corroboram com as afirmações dos autores Carlotto, Teixeira e Dias (2015) e M. A. P. Teixeira, Dias, Wottrich e Oliveira (2008) de que uma turma com mais tempo de relacionamento deve estar mais estruturada e solidificada entre os alunos (maiores valores de centralidade).

\section{Intermediação (betweenness)}

A intermediação mede o quanto um membro da rede atua como facilitador do fluxo de informações entre os demais atores da rede. Em relação à Turma 1 verificou-se baixos valores tanto na rede informal (variação entre $0,01 \%$ e $13,50 \%)$ quanto na rede formal $(0,01 \%$ a $16,89 \%)$. Acerca da Turma 2 verificou-se variação de $0,00 \%$ a $26,31 \%$ na rede informal e variação de $0,00 \%$ a $49,93 \%$ na rede formal.

A medida betweenness apresentou diferença significativa entre a rede informal e formal apenas para a Turma $2(\mathrm{Z}=-2,359, \mathrm{p}=0,018)$, verificada por meio do teste não paramétrico de Wilcoxon, sendo maior para o relacionamento pessoal (valor médio de intermediação $M=9,0$ ) do que para o profissional $(\mathrm{M}=8,0)$.

Além disso, não foram obtidas diferenças significativas entre as duas turmas, indicando que a medida não sofreu alteração levando-se em conta a diferença no tempo de relacionamento delas. Visualizando os resultados gerais, foi possível notar que nenhuma das turmas conseguiu atingir um grau de intermediação superior a 50\%, indicando o quão baixo o grau de intermediação dos alunos de ambas as turmas é. Nesse sentido, também foram identificados diversos atores sem nenhum grau de intermediação, tanto na Turma 1 quanto na Turma 2, reforçando os baixos valores encontrados. Com base na literatura, poder-se-ia esperar que a turma 2 deveria apresentar medidas de intermediação maiores, porém isso não foi constatado nesta pesquisa.

\section{Proximidade (closeness)}

A medida closeness mede o grau de proximidade que um ator está em relação aos demais atores da mesma rede, estando dividida ainda, em incloseness e outcloseness. Para a Turma 1 a medida incloseness da rede informal mostrou uma variação (de $20,90 \%$ a $38,68 \%$ ) e a medida outcloseness apresentou maior variação (de 2,38\% a 68,34\%). Na rede formal, a medida incloseness obteve uma maior variação (de 32,28\% a 63,08\%) e a medida outcloseness, variou entre 32,80\% e 80,40\%. 
A Turma 2 por sua vez, apresentou variação considerável da medida incloseness da rede informal $(1,00 \%$ a $33,00 \%)$ e a medida outcloseness apresentou variação similar (1,00\% e $31,00 \%)$. A medida incloseness da rede formal indicou baixa variação (de $25,00 \%$ a $34,00 \%$ ) e a medida outcloseness, por outro lado, obteve maior variação (de $1,00 \%$ a $63,00 \%)$.

Para a Turma 1 apenas a medida incloseness apresentou diferença significativa entre a rede informal e formal, verificada por meio do teste não paramétrico de Wilcoxon $(Z=-5,633, p=0,000)$, sendo maior para a rede formal. Já no caso da Turma 2, ambas as medidas de incloseness e outcloseness mostraram diferenças significativas entre as redes, também verificadas por meio do teste não paramétrico de Wilcoxon $(\mathrm{Z}=-5,661, \mathrm{p}=0,000$ e $\mathrm{Z}=-6,393, \mathrm{p}=0,000$, respectivamente), também maior para a rede formal.

Além disso, foram encontradas diferenças significativas entre as duas turmas para as quatro medidas analisadas, verificadas por meio do teste não paramétrico de Mann-Whitney. Primeiramente, foram observadas diferenças significativas entre os incloseness e outcloseness entre as redes informais ( $\mathrm{U}=217, \mathrm{p}=0,000$ e $\mathrm{U}=59, \mathrm{p}=0,000$, respectivamente), sendo ambas as medidas maiores para a Turma 1. Resultado semelhante ocorreu em relação à rede formal, com diferenças significativas observadas entre os incloseness e outcloseness formais ( $\mathrm{U}=8, \mathrm{p}=0,000$ e $\mathrm{U}=653$, $\mathrm{p}=0,000$, respectivamente), sendo novamente ambas as medidas maiores para a Turma 1 . Isso indica que, novamente não houve confirmação com resultados da literatura. A maior proximidade foi encontrada entre os alunos iniciantes do segundo semestre (Turma 1) do que entre os alunos veteranos do sexto semestre (Turma 2).

As diferenças encontradas entre as redes formais e informais nas turmas 1 e 2 em algumas das medidas de intermediação e de proximidade indicam a não confirmação do que diz a literatura a respeito dos aspectos formal e informal, enfatizada pelos autores McEvily et al. (2014) e Soda e Zaheer (2012).

\section{Centros e periferias (core periphery)}

Analisando-se a rede informal da turma 1 com base na medida centro-periferia, identifica-se o centro com uma densidade de 66,3\%, isto é, alunos com mais relacionamento da rede. Os alunos considerados periféricos (com pouco relacionamento) apresentam uma densidade de relacionamento de $16,6 \%$. A rede formal apresenta resultado mais modesto em relação ao relacionamento entre os grupos do centro (42,4\% de densidade) e os da periferia, com $13,8 \%$.

A rede informal do sexto semestre (turma 2), apresentou menor relacionamento entre os grupos do centro e os da periferia. As densidades foram de $29,2 \%$ e $8,7 \%$, respectivamente. A rede formal do sexto semestre repetiu o resultado com densidade de $24,8 \%$ para o centro e $7,2 \%$ na periferia.

Com base nesses resultados, pôde-se constatar que o relacionamento tanto informal quanto formal é menor na turma do sexto semestre quando comparado com a turma que praticamente está iniciando o curso (turma do segundo semestre). Dessa forma o resultado não confirma as informações apresentadas no referencial teórico, isto é, as redes não apresentam padrões similares e indicam menor relacionamento entre os alunos do que se esperaria. Parece ocorrer uma seleção no relacionamento entre os alunos, com cada um se relacionando com menos colegas.

\section{Reciprocidade (Reciprocity)}

Observou-se que os estudantes do segundo semestre possuem um percentual de relacionamento recíproco formal menor do que no relacionamento informal. O percentual de relações formais (bidirecionais) recíprocas entre os estudantes é de 36,63\%, enquanto que o de informais é de 55,42\%. Ou seja, o relacionamento informal apresenta maior reciprocidade.

Os estudantes do sexto semestre possuem um percentual de relacionamento recíproco formal maior do que o percentual no relacionamento informal. De fato, o percentual de relações formais (bidirecionais) recíprocas entre os estudantes neste semestre é de $43,44 \%$, enquanto que o de informais é de $40,77 \%$. Estes resultados sugerem que, à medida que os alunos evoluem de um semestre para outro, 
o nível de relacionamento formal assume a liderança e o informal fica em segundo plano (Tabela 2) para a turma com mais tempo de relacionamento.

Tabela 2

Reciprocidade das Redes Informal e Formal - Turmas 1 e 2

\begin{tabular}{lllll} 
& Turma 1 & \multicolumn{3}{c}{ Turma 2 } \\
\cline { 2 - 5 } & Informal & Formal & Informal & Formal \\
\hline Geral & $55,42 \%$ & $36,63 \%$ & $40,77 \%$ & $43,44 \%$ \\
\hline
\end{tabular}

Nota. Fonte: Elaborada pelos autores.

A comparação das medidas de reciprocidade formal e informal difere em relação aos cursos do segundo e sexto semestres, sendo a informal maior que a formal no segundo semestre e a formal maior que a informal no sexto semestre. Esses resultados também estão em desacordo com os autores Maciel e Camargo (2015), que ressaltam ser uma vantagem o aumento das relações entre os integrantes de uma organização, uma vez que se esperaria uma maior reciprocidade na rede informal com maior tempo de relacionamento.

\section{Considerações Gerais}

O trabalho teve como objetivo comparar as redes sociais informais e formais de duas turmas distintas de alunos universitários, segundo suas percepções e com períodos de vida acadêmica diferente. Isso possibilitou a compreensão acerca das estruturas e dinâmicas gerais das redes das duas turmas analisadas, identificando e analisando suas possíveis diferenças e similaridades. Mais relevante foi constatar que os resultados da pesquisa não confirmaram os dois aspectos analisados da literatura: a tendência à similaridade entre as redes formais e informais e o fator tempo como determinante para o fortalecimento dos relacionamentos.

De fato, os autores McEvily et al. (2014) e Soda e Zaheer (2012) ressaltaram a importância da interação entre as redes formais e informais, o que não foi encontrado nesse trabalho. Os valores diferentes encontrados nas medidas utilizadas da análise de redes sociais indicam que as redes formal e informal em ambas as turmas não se mostram similares.

A similaridade de padrões de relacionamento, analisada neste trabalho com base nas medidas da análise de redes sociais, segundo os autores supracitados, seria fundamental para que se desenvolvesse uma sinergia na rede. Isso se torna ainda mais agravante ao considerar que se trata de um ambiente acadêmico, que demanda interação entre os alunos, a fim de haver troca de informações e compartilhamento de conhecimentos e experiências, conforme já indicado por M. R. F. Teixeira (2011) e M. T. Teixeira e Reis (2012).

Em segundo lugar, os autores Carlotto et al. (2015) e M. A. P. Teixeira et al. (2008) defenderam uma maior estruturação e solidificação dos relacionamentos entre os alunos com o passar do tempo, com um substancial aumento das relações nas redes. A variável tempo foi considerada relevante no estudo com atletas realizado por Genoíno e Siqueira (2017) e no trabalho de Vieira e Neiva (2009) sobre mudanças organizacionais. Porém, na comparação entre as redes formais e informais da turma iniciante com a turma veterana, tal fortalecimento também não foi encontrado. Pode-se dizer que houve o oposto, as redes decresceram em densidade no seu centro e também na sua periferia e apresentaram resultados diferentes na reciprocidade dos relacionamentos. Dessa forma, os dados encontrados devem ser novamente vistos com atenção, uma vez que a diminuição dos relacionamentos nas redes é contrária à orientação da literatura no que diz respeito a um melhor aproveitamento das oportunidades acadêmicas, tanto de âmbito pessoal quanto profissional. 
Apesar de os resultados encontrados neste trabalho serem válidos somente para as turmas pesquisadas, algumas reflexões devem ser realizadas. Será que a estratégia de ensino por meio da integração social (Davis et al., 1989) realmente ocorre na prática, como defendido pelos profissionais de ensino e pelos pesquisadores da área? As relações que os alunos desenvolvem durante a vida universitária, que são imperativas para eles nessa fase (M. T. Teixeira \& Reis, 2012), estão sendo verdadeiramente suficientes para um melhor aprimoramento pessoal e profissional? Estão as redes desenvolvidas nas universidades e nas organizações, de fato, em concordância com o ambiente em que se inserem e de acordo com o que se demandam delas? Será que o maior tempo de relacionamento entre os indivíduos faz com que os mesmos sejam mais seletivos, relacionem-se de forma mais intensa com alguns e deixem de se relacionar com os demais, diminuindo a rede de relacionamento formal e informal? E, não menos importante é indagar se as redes formais e informais dentro das organizações padecem dos mesmos problemas verificados nas turmas pesquisadas, quais sejam: a não similaridade entre as redes e o fator tempo como não determinante para o fortalecimento dos relacionamentos. São sugeridas que essas e outras reflexões pertinentes sejam investigadas por estudos futuros, inclusive nos relacionamentos intraorganizacionais.

Com esses resultados, o papel do professor além de todas as atividades que já exerce, parece ser o de alavancar os relacionamentos entre os alunos, tanto nas tarefas individuais e em grupo (rede formal) quanto no fortalecimento dos relacionamentos informais, isto é, maior troca de informações em nível geral. A instituição de ensino deve oferecer momentos e eventos que auxiliem nesse sentido, o que também pode ser proposto para as organizações.

O trabalho apresenta limitações tais como a pesquisa realizada somente entre alunos de duas turmas de um curso de Administração, amostra não probabilística, não ser uma pesquisa longitudinal, apesar de apresentar duas turmas diferentes com tempos diferentes de relacionamento, e por não contemplar de forma direta a atuação do professor em sala de aula e de funcionários da instituição de ensino. Essas limitações podem instigar estudos futuros.

Embora o estudo tenha alcançado os objetivos propostos, pesquisas que usam dados transversais podem comprometer a generalização dos resultados. Por esta razão, sugere-se que estudos futuros utilizem dados longitudinais ou mais de uma instituição de ensino.

\section{Referências}

Azevedo, T. B., \& Rodriguez, M. V. R. Y. (2010). Softwares para análise de redes sociais-ARS. Congress Nacional de Excelência em Gestão, Niterói, RJ, Brasil, 6.

Basov, N., \& Wuehr, D. (2012). Intra-organizational communication networks and success in innovation projects: Comparing the cases of German mechanical engineering companies [Working Papers]. Centre for German and European Studies, Bielefeld University, Sankt-Peterburg, Rússia. https://doi.org/10.13140/2.1.2086.7527

Bastos, V. B., \& Santos, M. V. (2007). Redes sociais informais e compartilhamento de significados sobre mudança organizacional. Revista de Administração de Empresas, 47(3), 1-13. http://doi.org/10.1590/S0034-75902007000300003

Brandes, U., Kenis, P., \& Raab, J. (2005). La explicación a través de la visualización de redes. REDES: Revista Hispana para el Análisis de Redes Sociales, 9(3), 1-19. https://doi.org/10.5565/rev/redes.75

Burkhardt, M. E. (1994). Social interaction effects following a technological change: A longitudinal investigation. The Academy of Management Journal, 37(4), 869-898. http://doi.org/10.2307/256603 
Carlotto, R. C., Teixeira, M. A. P. T., \& Dias, A. C. G. (2015). Adaptação acadêmica e coping em estudantes universitários. Psico-USF, 20(3), 421-432. Recuperado de http://www.scielo.br/pdf/pusf/v20n3/2175-3563-pusf-20-03-00421.pdf

Conde, R. de N. C., \& Farias, M. C., Filho (2016). Relações informais influenciadas pela estrutura formal: Uma análise de redes sociais de gestores. Revista de Ciências da Administração, 18(46), 68-80. http://doi.org/10.5007/2175-8077.2016v18n4

Davis, C., Silva., M. A. S. S., \& Esposito, Y. (1989). Papel e valor das interações sociais em sala de aula. Cadernos de Pesquisa da Fundação Carlos Chagas, (71), 49-54.

Diniz, A. Q., Santana, D. T., \& Rodrigues, M. C. (2012). Comunicação organizacional (Trabalho Premiado). Anais do Congresso de Pesquisa Científica: Inovação, Ética e Sustentabilidade, Garça, SP, Brasil, 2.

Enyia, D. C., \& Eze, O. L. (2016). The role of formal and informal communication in determining employee affective and continuance commitment in oil and gas companies. International Journal of Advanced Academic Research, Social \& Management Sciences, 2(9), 33-44.

Fittipaldi, M. A. S., Donaire, D., Farina, M. C., \& Araújo, M. F. (2014). O uso da análise de redes sociais para identificar a competição em um cluster comercial planejado. Anais do Encontro Internacional sobre Gestão Empresarial e Meio Ambiente, São Paulo, SP, Brasil.

Genoíno, R. K., \& Siqueira, J. P. L. (2017). O comprometimento organizacional, a qualidade técnica e o tempo na equipe como antecedentes da centralidade dos atletas nas redes de confiança de equipes esportivas. Contextus, Revista Contemporânea de Economia e Gestão, 15(2), 86-119.

Giglio, E. M., \& Ryngelblum, A. L. (2009). Uma investigação sobre o ator consumidor na rede de pirataria e uma proposta de alternativa de estratégia de combate. Revista de Administração Mackenzie, 10(4), 131-155. http://doi.org/10.1590/S1678-69712009000400007

Hanneman, R. A., \& Riddle, M. (2005). Introduction to social network methods (publicado na forma digital). University of California, Riverside. Retrieved from http://faculty.ucr.edu/ hanneman/

Kolaczyk, E. D., \& Csárdi, G. (2014). Statistical analysis of network data with R. New York, NY: Springer.

Krackhardt, D., \& Hanson, J. (1993). Informal networks: The company behind the chart. Harvard Business Review, 71(4), 104-111.

Lipnack, J., \& Stamp, J. (1992). Networks, redes de conexão: Pessoas conectando-se com pessoas. São Paulo: Aquarela.

Macambira, M. O., \& Bastos, A. V. B. (2009). Comprometimento organizacional e redes sociais informais: A estrutura das relações interpessoais e o vínculo com a organização. In A. Paredes (Compilador), Redes sociales: Análisis e intervención psicosociales (pp. 179-202). Recuperado de:https://www.academia.edu/11310589/Universidad_de_Aconcagua_Redes_Sociales_An\%C3 $\%$ A1lisis_e_intervenci\%C3\%B3n_psicosociales

Maciel, C. O., \& Camargo, C. (2015). Conexão Social Intraorganizacional, Suporte no Trabalho e Identificação Organizacional [3a Edição Especial]. Revista de Administração Contemporânea, 19, 348-366. Recuperado de http://www.scielo.br/pdf/rac/v19nspe3/1415-6555-rac-19-spe300348.pdf. http://doi.org/10.1590/1982-7849rac20152017

Marques, J. B. V., Freitas, D. de (2017). Fatores de caracterização da educação não formal: Uma revisão da literatura. Educação e Pesquisa, 43(4), 1087-1110. http://doi.org/10.1590/s15179702201701151678 
Marteleto, R. M. (2001). Análise de redes sociais: Aplicação nos estudos de transferência da informação. Ciência da Informação, 30(1), 71-81. http://doi.org/10.1590/S0100-19652001000100009

McEvily, B., Soda, G., \& Tortoriello, M. (2014). More formally: Rediscovering the missing link between formal organization and informal social structure. The Academy of Management Annals, 8(1), 299-345. https://doi.org/10.1080/19416520.2014.885252

Meirelles, C. L., Sacomano, J. B., Telles, R., \& Siqueira, J. P. L. (2014a). Gestão de pessoas nas pequenas e medias empresas: Mapeamento das redes informais, internas nas organizações, como ferramenta de recursos humanos. Revista Espacios, 35(5), 16.

Meirelles, C. L., Sacomano, J. B., Telles, R., \& Siqueira, J. P. L. (2014b, March). Gestão do conhecimento: $\mathrm{O}$ uso do programa Ucinet 6.0 como sistema de informação para identificar mudanças organizacionais nas PMEs. Proceedings of the International Conference on Engineering and Technology Education. Guimarães, Portugal, 13.

Miranda, M. G. C., Liboreiro, K. R., \& Borges, R. (2017). Socializar para adequar-se: Como redes sociais intraorganizacionais podem influenciar a adequação indivíduo-organização. Revista de Administração Contemporânea, 21(5), 666-684. Recuperado de http://www.scielo.br/pdf/rac/v21n5/1415-6555-rac-21-05-00666.pdf. http://doi.org/10.1590/1982-7849rac2017160189

Mohammadi, H., Hosseinzadeh, M., \& Kazemi, A. (2012). Women's position in intra organizational informal relationship networks: An application of network analysis approach. Procedia - Social and Behavioral Sciences, 41, 485-491. https://doi.org/10.1016/j.sbspro.2012.04.059

Nishi, J. M. (2014). Estrutura formal e redes sociais informais: Um estudo comparativo entre organização pública e privada (Dissertação de mestrado). Universidade Federal de Santa Maria, Centro de Ciências Sociais e Humanas, Programa de Pós-graduação em Administração, Santa Maria, RS, Brasil.

Nishi, J. M., Lobler, M. L., Costa, V. M. F., \& Lopes, L. F. D. (2014). Redes sociais e configurações de poder: Estudo de caso em uma escola pública. Anais do Congresso Nacional de Excelência em Gestão, Rio de Janeiro, RJ, Brasil, 10. Recuperado de http://www.inovarse.org/sites/default/files/T14_0379_5.pdf

Pascotto, M. P., Farina, M. C., Rodrigues, T. H. P. T., \& Dugo, J. C. (2013). Análise de rede social para mensuração das estruturas formais e informais. Revista de Administração da UFSM, 6, 179-194. http://doi.org/10.5902/198346598808

Petterson, A. R., \& Castro, M. (2016). Estruturas de redes de cooperação interorganizacional: O caso da feira do produtor. Revista Espacios, 37(20), 8.

Ribeiro, L. C., \& Rodriguez, M. V. R. Y, (2016). Informal social network and thechnical knowledge in R\&D. Revista Eletrônica de Administração, 22(3), edição 85, 280-311. Retrieved from http://www.scielo.br/pdf/read/v22n3/1413-2311-read-22-3-0280.pdf. http://doi.org/10.1590/1413-2311.02814.50197

Schneider, H. N. (2002). A escola como uma organização de aprendizagem interativa informatizada. Anais do Simpósio Brasileiro de Informática na Educação, São Leopoldo, RS, Brasil, 13.

Silva, A. F. da, Costa, V. M. F., Zamberlan, C. O., \& Costa, V. F. (2011). Análise de redes sociais informais - ferramenta para o compartilhamento do conhecimento organizacional. Anais do Encontro Nacional da Associação Nacional de Pós-graduação e Pesquisa em Administração, Rio de Janeiro, RJ, Brasil, 35. 
Soda, G., \& Zaheer, A. (2012). A network perspective on organizational architecture: Performance effects of the interplay of formal and informal organization. Strategic Management Journal, 33(6), 751-771. https://doi.org/10.1002/smj.1966

Teixeira, M. A. P., Dias, A. C. G., Wottrich, S. H., \& Oliveira, A. M. (2008). Adaptação à universidade em jovens calouros. Psicologia Escolar e Educacional, 12(1), 185-202. http://doi.org/10.1590/S1413-85572008000100013

Teixeira, M. R. F. (2011). Redes de conhecimento em ciências e o compartilhamento do conhecimento (Tese de doutorado). Universidade Federal do Rio Grande do Sul, Instituto de Ciências Básicas da Saúde. Programa de Pós-Graduação em Educação em Ciências: Química da Vida e Saúde, Porto Alegre, RS, Brasil.

Teixeira, M. T., \& Reis, M. F. (2012). A organização do espaço em sala de aula e as suas implicações na aprendizagem cooperativa. Revista Meta: Avaliação, 4(11), 162-187. http://doi.org/10.22347/2175-2753v4i11.138

Waldstrom, C. (2001). Formal and informal interpersonal relationships: Interaction of networks in the academic environment [Working Papers $\mathrm{n}^{\circ}$ 2001-4]. Aarhus V, Denmark., Retrieved from https://econpapers.repec.org/paper/hhbaardom/2001_5f004.htm

Vieira, S. R. F., \& Neiva, E. R. (2009, setembro). Redes sociais no contexto de mudança organizacional. Anais do Encontro Nacional da Associação Nacional de Pós-graduação e Pesquisa em Administração, São Paulo, SP, Brasil, 33.

Wasserman, S., \& Faust, K. (1994). Social network analysis: Methods and applications. New York: Cambridge University Press.

Zanini, M. T., Migueles, C. P., Colmerauer, M., \& Mansur, J. (2013). Os elementos de coordenação informal em uma unidade policial de operações especiais. Revista de Administração Contemporânea, 17(1), 106-125. Recuperado de http://www.scielo.br/pdf/rac/v17n1/v17n1a07.pdf. 65552013000100007

\author{
Autores \\ Sandra Bergamini Leonardo \\ Avenida Goiás 3400, 09550-051, São Caetano do Sul, SP, Brasil \\ E-mail: sandraleonardo@uol.com.br \\ Milton Carlos Farina \\ Avenida Goiás 3400, 09550-051, São Caetano do Sul, SP, Brasil \\ E-mail: milton.farina@uscs.edu.br \\ Taís Pasquotto Andreoli \\ Avenida Goiás 3400, 09550-051, São Caetano do Sul, SP, Brasil \\ E-mail: tais_pa@hotmail.com \\ Ana Paula Morais Boteon de Lima \\ Avenida Goiás 3400, 09550-051, São Caetano do Sul, SP, Brasil \\ E-mail: paula@farisaduaneira.com.br
}

\title{
Contribuições
}

$1^{\circ}$ autor: Participou efetivamente na elaboração do artigo intitulado "Relacionamentos Interpessoais Formal e Informal: Interação das Redes no Ambiente Acadêmico" e em específico: na montagem do experimento, coleta dos dados, tabulação, criação das tabelas e figuras, redação e revisão do texto e na padronização das normas de acordo com a revista. 
$2^{\circ}$ autor: Participou efetivamente na elaboração do artigo intitulado "Relacionamentos Interpessoais Formal e Informal: Interação das Redes no Ambiente Acadêmico" e em específico: na orientação do trabalho, na montagem do experimento, análise estatística dos dados e na redação e revisão do texto.

$3^{\circ}$ autor: Participou efetivamente na elaboração do artigo intitulado "Relacionamentos Interpessoais Formal e Informal: Interação das Redes no Ambiente Acadêmico" e em específico: na montagem do experimento, coleta dos dados, análise estatística dos dados e na redação do texto.

$4^{\circ}$ autor: Participou efetivamente na elaboração do artigo intitulado "Relacionamentos Interpessoais Formal e Informal: Interação das Redes no Ambiente Acadêmico" e em específico: na montagem do experimento, coleta dos dados, tabulação e criação das tabelas e figuras e na redação do texto.

\section{Financiamento}

Os autores declaram que não houve financiamento de qualquer tipo.

\section{Conflito de Interesses}

Os autores declaram que não há conflito de interesses.

\section{Verificação de Plágio}

A RAC mantém a prática de submeter todos os documentos aprovados para publicação à verificação de plágio, mediante o emprego de ferramentas específicas, e.g.: iThenticate.

\section{Material Suplementar}

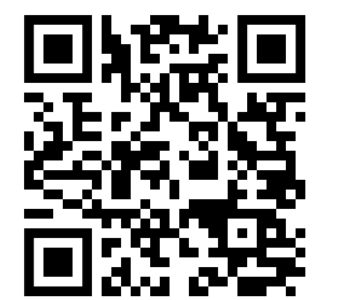

Todos os dados e materiais foram disponibilizados publicamente por meio da plataforma Mendeley e podem ser acessados em: Bergamini Leonardo, Sandra; Farina, Milton Carlos; Pasquotto Andreoli, Taís; Morais Boteon de Lima, Ana Paula (2019), "Data for "Formal and Informal Interpersonal Relationships: interaction of networks in the academic environment" published by RAC-Revista de Administração Contemporânea”, Mendeley Data, v1. Recuperado de http://doi.org/10.17632/by5rhc9z9z.1 